\title{
Emergency Short-Stay Unit as an Effective Alternative to In-Hospital Admission for Acute Exacerbation of Chronic Heart Failure
}

\author{
Albert Salazar, Luis Garcia-Eroles, Gemma Craywinckel, Xavier Corbella \\ Hospital de la Santa Creu i Sant Pau, Barcelona, Spain \\ Email: ASalazar@santpau.cat
}

Received 6 July 2014; revised 5 August 2014; accepted 4 September 2014

Copyright (C 2014 by authors and Scientific Research Publishing Inc.

This work is licensed under the Creative Commons Attribution International License (CC BY). http://creativecommons.org/licenses/by/4.0/

\section{Abstract}

Study Objective: To determine whether a new emergency department short-stay unit (EDSSU) was an effective alternative to conventional hospital units (HU) for acute exacerbation of chronic heart failure patients. Methods: Design: A comparative analysis was used to identify differences among patients admitted to EDSSU $(n=1546)$ and those admitted to the internal medicine $(n=552)$ or cardiology wards $(n=336)$ during the period of the study (January 1,2008 to December 31, 2012). Setting: The study was performed at Sant Pau Hospital, a 500-bed teaching tertiary care referral center in Barcelona, Spain. The ED attends about 144,000 emergency visits per year. Participants: We studied retrospectively the characteristics of patients hospitalized with an acute exacerbation of chronic heart failure between January 1, 2008 and December 31, $2012(n=2434)$. We chose charts of patients from the hospital discharge database and selected according to the 9 th revision of the International Classification of Diseases Codes. We used the computerized database to obtain outcome data on all patients. Results: Statistically significant differences were found in terms of mean age (HU: $77.38(14.44)$ years versus EDSSU: 82.43 (8.72) years; $p<0.001$ ), mean length of stay (HU: 11.57 (10.42) days versus EDSSU: 4.75 (3.18) days; $p<0.001$ ), mortality (HU: $14.0 \%$ versus EDSSU: $4.0 \% ; p<0.001$ ), but not for urgent readmission rate of 30 days or less (HU: $18.30 \%$ versus EDSSU: $18.30 \% ; p=0.998$ ). There were statistically significant differences regarding sex (HU women $=60.6 \%$; EDDSU women $=67.7 \% ; p<0.001$ ) and number of associated conditions (Charlson index HU $=1.25$, EDDSU $=0.90 ; p<0.001$ ). Conclusion: The EDSSU proved to be an effective and safe measure in emergency care of patients with acute heart failure (AHF).

\section{Keywords}

Emergency, Short-Stay, AHF

How to cite this paper: Salazar, A., Garcia-Eroles, L., Craywinckel, G. and Corbella, X. (2014) Emergency Short-Stay Unit as an Effective Alternative to In-Hospital Admission for Acute Exacerbation of Chronic Heart Failure. International Journal of Clinical Medicine, 5, 1200-1206. http://dx.doi.org/10.4236/ijcm.2014.519153 


\section{Introduction}

Observation and short-stay units are becoming common in hospitals and are an increasingly important component of the modern emergency department (ED) because they are an alternative to admission or discharge. The criteria for admission to an ED short-stay unit (EDSSU) should be consistent with four principles: first, clearly identified patient care goals; second, limited need for intense medical services; third, limited severity of illness; and fourth, the patient should have a clinical condition that is appropriate for observation. The concept and goal of an EDSSU is to develop rapid diagnostic and treatment protocols that will avoid inpatient admissions for a variety of reversible acute medical conditions [1]-[7]. The development of ED chest pain evaluation units allows the rapid evaluation and treatment of patients with suspected acute coronary syndrome without hospitalization. Treatment of selected patients with acute exacerbation of chronic obstructive pulmonary disease (COPD) in an ED diagnostic and treatment unit rather than the inpatient ward results in the safe discharge of most such patients and hence the reduction in their hospitalization rate [8]. Furthermore, some authors have reported a higher level of patient satisfaction with an ED asthma observation unit than with routine inpatient hospitalization [9].

The utilization of health care resources by elderly patients with acute heart failure (AHF) is immense [10] [11]. Acute exacerbation of chronic heart failure causes frequent hospitalizations in winter, when there is often a coexisting in-hospital bed crisis and ED overcrowding [12]-[16]. However, there are few data to establish the duration of hospitalization in individual patients to achieve maximal benefit and to identify those AHF patients suitable for early discharge from the hospital [17]-[20].

The objectives of the present study were to determine whether the introduction of an EDSSU would be an effective and safe alternative setting to standard hospital units (HU) for the management of AHF.

\section{Methods}

The study was performed at Sant Pau Hospital, a five hundred-bed teaching tertiary care referral center in Barcelona, Spain. The ED has more than 144,000 patient visits each year. The ED is staffed by internists 24 hours a day. An EDSSU was established and fully operational in 2008. It comprises thirty beds and is supervised by the attending emergency physicians and nurses.

The study was a retrospective analysis of patients hospitalized with AHF. We analyzed patients over the age of 18 years who were consecutively hospitalized with worsened dyspnea diagnosed as exacerbation of chronic heart failure over the period of January 2008 to December 2012. We chose charts of patients from the hospital discharge database and selected according to the Ninth Revision of the International Classification of Diseases codes [21]. We used the Minimum Basic Data Set (MBDS) computerized database to obtain outcome data on all patients.

Patients were excluded from the study if they had pulmonary or cardiac diagnoses at the time of hospital admission other than or in addition to AHF. Patients were also excluded if the primary reason for hospital admission was not exacerbation of heart failure, if they had severe congestive heart failure related to COPD, if they had chest pain consistent with myocardial ischemia, or if they were intubated and ventilated on the day of admission.

Three patient groups were studied. The EDSSU group (Group 1) consisted of adults with acute exacerbation of chronic heart failure visited in the ED between January 1, 2008 and December 31, 2012, and admitted to an emergency department short-stay unit after their emergency visits. The other two groups comprised adults with the same diagnosis visited during the same period of time and admitted to conventional hospital units (HU), either internal medicine (Group 2) or cardiology (Group 3) wards, after their emergency visits.

AHF management and patient disposition were left to the discretion of the individual physician. Discharge medications for all three groups included diuretics and vasodilator therapy. We measured the unscheduled visits for treatment of exacerbation of heart failure at the ED. The length of stay and mortality rate in each health care setting was abstracted from the hospital information systems.

Statistical analysis was performed using IBM-SPSS V21 software package. Differences between groups were assessed with t tests, ANOVA and $\chi^{2}$ procedures, with $p$ values less than 0.05 considered significant. Scheffé method and Bonferroni correction was applied for multiple comparisons.

\section{Results}

A total of 2434 episodes were included in the study between January 2008 and December 2012 . Group 1 
(EDSSU) had 1546 AHF patients, Group 2 (internal medicine) 552 patients and the Group 3 (cardiology) 336. There were statistically significant differences among the three groups with regard to sex [(internal medicine vs cardiology $(p<0.001)$ and EDSSU vs cardiology $(p<0.001)$ ], number of associated conditions at the time of ED presentation [internal medicine vs cardiology $(p<0.01)$, EDSSU vs cardiology $(p<0.001)$ and internal medicine vs. EDSSU $(p<0.001)$ ], age [internal medicine vs cardiology $(p<0.001)$, EDSSU vs cardiology $(p<$ $0.001)$ and internal medicine vs. EDSSU $(p<0.05)$ ], length of stay [internal medicine vs cardiology $(p<0.01)$, EDSSU vs cardiology $(p<0.001)$ and internal medicine vs. EDSSU $(p<0.001)$ ] and mortality [internal medicine vs cardiology $(p<0.001)$, EDSSU vs cardiology $(p<0.05)$ and internal medicine vs. EDSSU $(p<0.001)$ ]. There no were statistically significant differences among the three groups in urgent readmission rate of 30 days or less. Main differences are shown in Table 1 and Graphs 1-6.

Table 1. Differences among the three groups.

\begin{tabular}{|c|c|c|c|c|c|c|c|}
\hline Indicator & $\begin{array}{c}\text { Group } 1 \\
\text { EDSSU } \\
(\mathrm{n}=1546)\end{array}$ & $\begin{array}{c}\text { Group } 2 \\
\text { internal medicine } \\
\quad(\mathrm{n}=552)\end{array}$ & $\begin{array}{c}\text { Group } 3 \\
\text { cardiology } \\
(\mathrm{n}=336)\end{array}$ & $p$ & $\begin{array}{c}\quad p \\
\text { Group 1- } \\
\text { Group } 2\end{array}$ & $\begin{array}{c}\text { p } \\
\text { Group 1- } \\
\text { Group } 3\end{array}$ & $\begin{array}{c}p \\
\text { Group 2- } \\
\text { Group 3 }\end{array}$ \\
\hline Age & $82.43(8.72)$ & 83.70 (8.39) & $67.00(13.73)$ & 0.000 & 0.027 & 0.000 & 0.000 \\
\hline Length of stay & 4.75 (3.18) & $10.93(9.64)$ & $12.63(11.54)$ & 0.000 & 0.000 & 0.000 & 0.001 \\
\hline Charlson index & 0.90 (1.09) & $1.15(1.44)$ & $1.41(1.42)$ & 0.000 & 0.000 & 0.000 & 0.007 \\
\hline Mortality & $4.00 \%$ & $18.10 \%$ & $7.10 \%$ & 0.000 & 0.000 & 0.038 & 0.000 \\
\hline Urgent readmission in 30 days & $18.30 \%$ & $21.20 \%$ & $14.10 \%$ & 0.043 & 0.502 & 0.224 & 0.129 \\
\hline Women & $67.70 \%$ & $69.40 \%$ & $46.10 \%$ & 0.000 & 1.000 & 0.000 & 0.000 \\
\hline
\end{tabular}

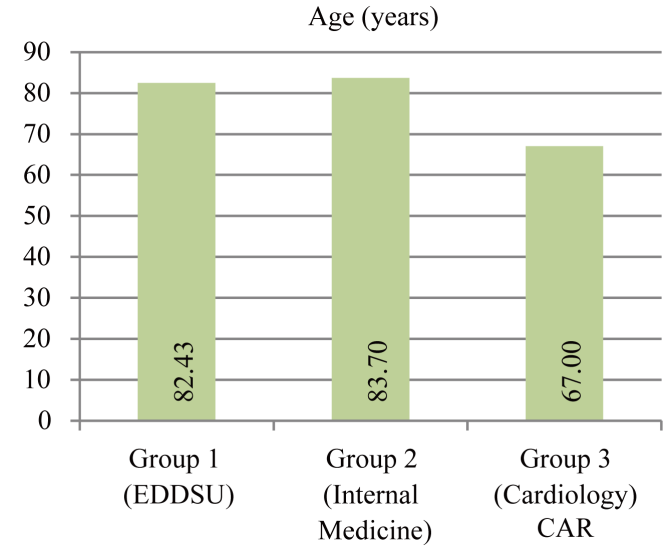

Graph 1. Age.

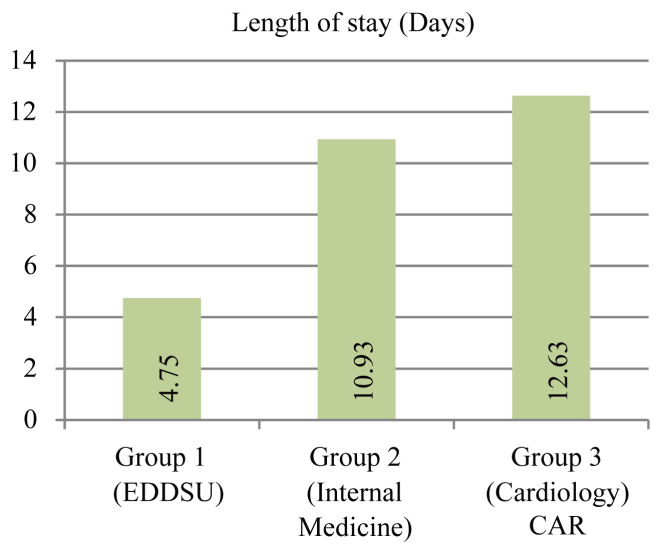

Graph 2. Length of stay (days). 


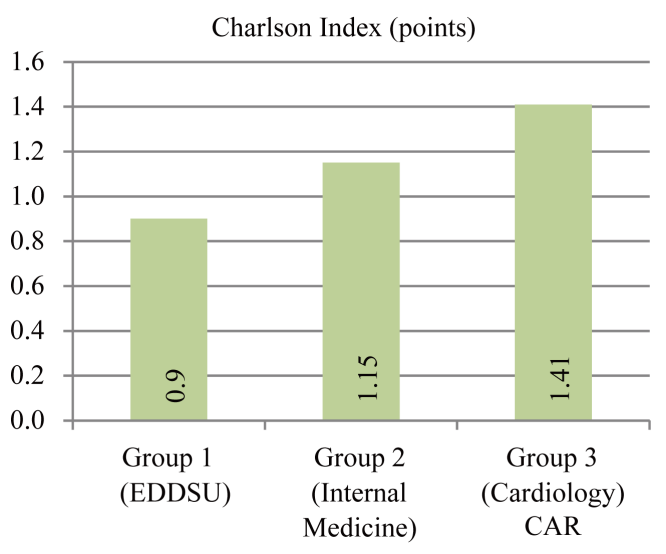

\section{Graph 3. Charlson index (points).}

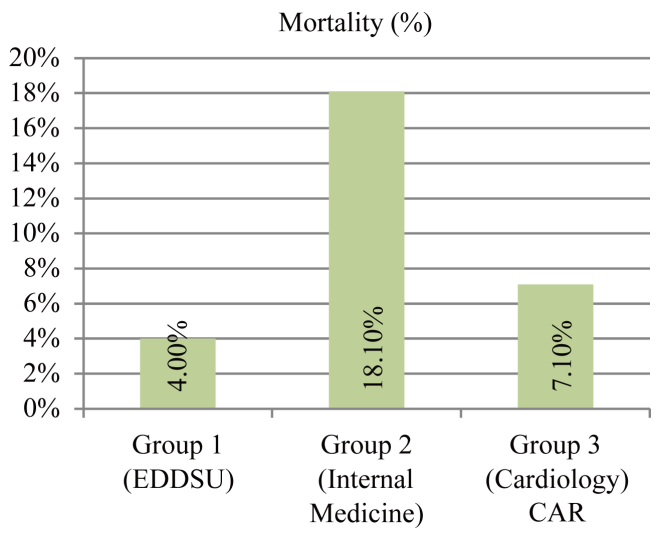

Graph 4. The rate of mortality.

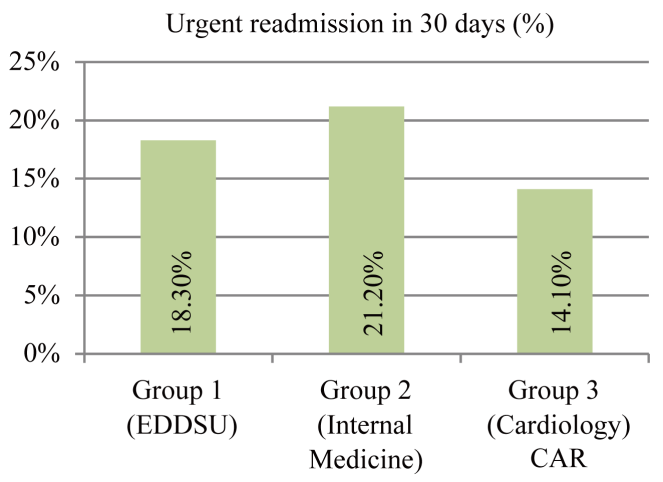

Graph 5. Urgent readmission in 30 days.

\section{Discussion}

Emergency admissions are continuing to rise. The causes of the massive use of the urban ED during winter are complex, but respiratory infections are definitely a major factor [22]-[27]. In previous studies, we reported how the implementation of particular interventions such as replacing residents with staff physicians or the opening of an EDSSU for those patients predicted to need a mean of a 3-day hospitalization resulted in shorter lengths of stays in the ED and might help to alleviate crisis from the ED overcrowding [1] [28]-[32]. Recently, we have published our experience with an EDSSU as an effective and safe alternative to standard inpatient hospitalization during winter for COPD exacerbation patients [8]. In the present study we demonstrated that the introduction of an EDSSU at a tertiary university hospital was associated with a decrease in the AHF patients' length of stay. 


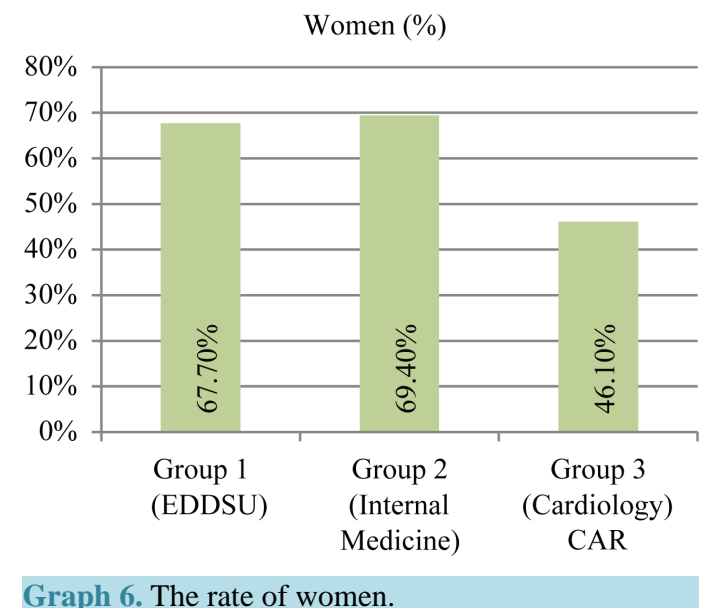

The strengths of our study include a large sample size and follow-up data on repeat ED visits after discharge. A total of 2434 adults were admitted diagnosed as AHF during the period of the study. Of these, 1546 admissions (63.5\%) were made to the EDSSU. The average length of stay in the EDSSU was 4.75 days and 10.93 days for those admitted to internal medicine ward and 12.63 days for those admitted to the cardiology ward. Discharge medications were similar for all groups. The rate of repeat urgent readmission rate within 30 days of discharge in the EDSSU group was $18.30 \%$ and $21.20 \%$ in Group 2 and $14.10 \%$ in Group 3 (no significant differences). AHF management and patient disposition were left to the discretion of the individual physician. It might be projected that if identical timing of evaluations were performed in the HU groups, similar results might have been achieved as in the EDSSU. It is likely that part of the increased length of stay for the HU groups is a feature of the nature and function of inpatient services. It is important to note that the mean hospital length of stay in $\mathrm{HU}$ also improved over the period of the study, which rules out a possible bias effect of less seriously ill AHF patients admitted to the EDSSU. The lack of a clear improvement in the occurrence of relapse during the 30-day period suggests the need for intensified ambulatory care or home care in the weeks after a short admission in an EDSSU. Also, it would be advantageous to identify those patients with AHF who are likely to succeed to respond to EDSSU therapy, without compromising quality of care and allow the physician to decide on the suitability of early discharge for the patients [33]-[35].

Patients were excluded from the study if they had pulmonary or cardiac diagnoses at the time of hospital admission other than or in addition to AHF. Both of these criteria were meant to minimize diagnostic confusion with other conditions, notably COPD, acute asthma and myocardial ischemia. There were statistically significant differences among groups with regard to sex or number of associated conditions at the time of ED presentation. However, several limitations must be addressed. We cannot exclude the possibility that some patients had repeat visits to their physicians' offices or other institutions in the 30 days after hospital discharge. However, we believe it unlikely that illness severity or repeat ED visits changed appreciably during the study period. Last, as we did not conduct a formal economic analysis, further work is needed to quantify the economic impact of the introduction of an EDSSU, both in general and, specifically, in the management of AHF.

\section{Conclusion}

In summary, we conclude that it is desirable to keep admissions to a minimum but to maintain a high quality of care. For these purposes, selected emergency patients with acute exacerbation of chronic heart failure can be effective and safely treated in the EDSSU as an alternative setting and, thus, avoid inpatient hospitalization that alleviated from winter in-hospital bed crises.

\section{Author Contributions}

Albert Salazar conceived the study, wrote the manuscript and takes responsibility for the paper as a whole. Luis Garcia provided statistical advice on study design. Gemma Craywinckel supervised data collection, managed and analyzed the data. Xavier Corbella contributed substantially to its revision. 


\section{References}

[1] Juan, A., Salazar, A., Alvarez, A., Perez, J.R., García, L. and Corbella, X. (2006) Effectiveness and Safety of an Emergency Department Short-Stay Unit as an Alternative to Standard Inpatient Hospitalization. Emergency Medicine Journal, 23, 833-837. http://dx.doi.org/10.1136/emj.2005.033647

[2] Moloney, E.D., Smith, D., Bennett, K., O’Riordan, D. and Silke, B. (2005) Impact of an Acute Medical Admission Unit on Length of Hospital Stay, and Emergency Department "Wait Times”. QJM: An International Journal of Medicine, 98, 283-289. http://dx.doi.org/10.1093/qimed/hci044

[3] Daly, S., Campbell, D.A. and Cameron, P.A. (2003) Short-Stay Units and Observation Medicine: A Systematic Review. Medical Journal of Australia, 178, 559-563.

[4] Rooney, T., Moloney, E.D., Bennett, K., O’Riordan, D. and Silke, B. (2008) Impact of an Acute Medical Admission Unit on Hospital Mortality: A 5-Year Prospective Study. QJM: An International Journal of Medicine, 101, 457-465. http://dx.doi.org/10.1093/qjmed/hcn025

[5] Scott, I., Vaughan, L. and Bell, D. (2009) Effectiveness of Acute Medical Units in Hospitals: A Systematic Review. International Journal for Quality in Health Care, 21, 397-407. http://dx.doi.org/10.1093/intqhc/mzp045

[6] Baugh, C.W., Venkatesh, A.K. and Bohan, J.S. (2011) Emergency Department Observation Units: A Clinical and Financial Benefit for Hospitals. Health Care Management Review, 36, 28-37. http://dx.doi.org/10.1097/HMR.0b013e3181f3c035

[7] Burkhardt, J., Peacock, W.F. and Emerman, C.L. (2005) Predictors of Emergency Department Observation Unit Outcomes. Academic Emergency Medicine, 12, 869-874. http://dx.doi.org/10.1111/j.1553-2712.2005.tb00965.x

[8] Salazar, A., Juan, A., Ballbé, R. and Corbella, X. (2007) Emergency Short-Stay Unit as an Effective Alternative to In-Hospital Admission for Acute Chronic Obstructive Pulmonary Disease Exacerbation. American Journal of Emergency Medicine, 25, 486-487. http://dx.doi.org/10.1016/j.ajem.2007.03.010

[9] Rydman, R.J., Roberts, R.R., Albrecht, G.L., et al. (1999) Patient Satisfaction with an Emergency Department Asthma Observation Unit. Academic Emergency Medicine, 6, 178-183. http://dx.doi.org/10.1111/j.1553-2712.1999.tb00152.x

[10] Robertson, J., McElduff, P., Pearson, S.-A., Henry, D.A., Inder, K.J. and Attia, J.R. (2012) The Health Services Burden of Heart Failure: An Analysis Using Linked Population Health Data-Sets. BMC Health Services Research, 12, 103. http://dx.doi.org/10.1186/1472-6963-12-103

[11] Ezekowitz, J.A., Bakal, J.A., Kaul, P., Westerhout, C.M. and Armstrong, P.W. (2008) Acute Heart Failure in the Emergency Department: Short and Long-Term Outcomes of Elderly Patients with Heart Failure. European Journal of Heart Failure, 10, 308-314. http://dx.doi.org/10.1016/j.ejheart.2008.01.014

[12] US Government Accountability Office (2009) Hospital Emergency Departments: Crowding Continued to Occur, and Some Patients Wait Longer than Recommended Time Frames, GAO-09-347. Washington DC.

[13] Forster, A.J., Stiell, I., Wells, G., Lee, A.J. and van Walraven, C. (2003) The Effect of Hospital Occupancy on Emergency Department Length of Stay and Patient Disposition. Academic Emergency Medicine, 10, 127-133.

[14] Kellermann, A.L. (2006) Crisis in the Emergency Department. The New England Journal of Medicine, 355, 1300-1303. http://dx.doi.org/10.1056/NEJMp068194

[15] Hoot, N.R. and Aronsky, D. (2008) Systematic Review of Emergency Department Crowding: Causes, Effects, and Solutions. Annals of Emergency Medicine, 52, 126-136. http://dx.doi.org/10.1016/j.annemergmed.2008.03.014

[16] Forero, R., McCarthy, S. and Hillman, K. (2011) Access Block and Emergency Department Overcrowding. Critical Care, 15, 216. http://dx.doi.org/10.1186/cc9998

[17] Peacock, W.F., Young, J., Collins, S., Diercks, D. and Emerman, C. (2006) Review Heart Failure Observation Units: Optimizing Care. Annals of Emergency Medicine, 47, 22-33. http://dx.doi.org/10.1016/j.annemergmed.2005.07.006

[18] Storrow, A.B., Collins, S.P., Lyons, M.S., Wagoner, L.E., Gibler, W.B. and Lindsell, C.J. (2005) Emergency Department Observation of Heart Failure: Preliminary Analysis of Safety and Cost. Congestive Heart Failure, 11, 68-72. http://dx.doi.org/10.1111/j.1527-5299.2005.03844.x

[19] Collins, S.P., Shauer, D.P., Gupta, A., Brunner, H., Storrow, A.B. and Eckman, M.H. (2009) Cost-Effectiveness Analysis of ED Decision Making in Patients with Non-High-Risk Heart Failure. The American Journal of Emergency Medicine, 27, 293-302. http://dx.doi.org/10.1016/j.ajem.2008.02.025

[20] Diercks, D.B., Peacock, W.F., Kirk, J.D. and Weber, J.E. (2006) ED Patients with Heart Failure: Identification of an Observational Unit-Appropriate Cohort. The American Journal of Emergency Medicine, 24, 319-324. http://dx.doi.org/10.1016/j.ajem.2005.11.014

[21] (1993) International Classification of Diseases, 9th Revision, Clinical Modifications. 4th Edition, Med-Index Publications, Salt Lake City. 
[22] Formiga, F., Vidaller, A., Salazar, A. and Pujol, R. (2005) Nonagenarian’s Use of Emergency Departments. Age \& Ageing, 34, 412-418. http://dx.doi.org/10.1093/ageing/afi100

[23] Kellermann, A.L. and Martinez, R. (2011) The ER, 50 Years on. The New England Journal of Medicine, 364, 22782279. http://dx.doi.org/10.1056/NEJMp1101544

[24] Han, J.H., Zhou, C., France, D.J., Zhong, S., Jones, I., Storrow, A.B., et al. (2007) The Effect of Emergency Department Expansion on Emergency Department Overcrowding. Academic Emergency Medicine, 14, 338-343.

[25] Khare, R.K., Powell, E.S., Reinhardt, G. and Lucenti, M. (2009) Adding More Beds to the Emergency Department or Reducing Admitted Patient Boarding Times: Which Has a More Significant Influence on Emergency Department Congestion? Annals of Emergency Medicine, 53, 575-585. http://dx.doi.org/10.1016/j.annemergmed.2008.07.009

[26] Greene, J. (2007) Emergency Department Flow and the Boarded Patient: How to Get Admitted Patients Upstairs. Annals of Emergency Medicine, 49, 68-70. http://dx.doi.org/10.1016/j.annemergmed.2006.11.020

[27] Wong, H.J., Morra, D., Caesar, M., Carter, M.W. and Abrams, H. (2010) Understanding Hospital and Emergency Department Congestion: An Examination of Inpatient Admission Trends and Bed Resources. Canadian Journal of Emergency Medicine, 12, 18-26.

[28] Salazar, A., Corbella, X., Onaga, H., Ramon, R., Pallarés, R. and Escarrabill, J. (2001) Impact of a Resident Strike on Emergency Department Quality Indicators at an Urban Teaching Hospital. Academic Emergency Medicine, 8, 804-808. http://dx.doi.org/10.1111/j.1553-2712.2001.tb00210.x

[29] Salazar, A., Corbella, X., Sánchez, J.L., Argimón, J.M. and Escarrabill, J. (2002) How to Manage the ED Crisis When Hospital and or ED Capacity Is Reaching Its Limits? Report about Implementation of Particular Interventions during the Christmas Crisis. European Journal of Emergency Medicine, 9, 79-80. http://dx.doi.org/10.1097/00063110-200203000-00019

[30] Salazar, A., Estrada, C., Porta, R., Lolo, M., Tomas, S. and Alvarez, M. (2009) Home Hospitalization Unit: An Alternative to Standard Inpatient Hospitalization from the Emergency Department. European Journal of Emergency Medicine, 16, 121-123. http://dx.doi.org/10.1097/MEJ.0b013e32831cbae2

[31] Gómez-Vaquero, C., Soler, A.S., Pastor, A.J., Mas, J.R.P., Rodriguez, J.J. and Virós, X.C. (2009) Efficacy of a Holding Unit to Reduce Access Block and Attendance Pressure in the Emergency Department. Emergency Medicine Journal, 26, 571-572. http://dx.doi.org/10.1136/emj.2008.066076

[32] Corbella, X., Ortiga, B., Juan, A., Ortega, N., Gómez, C., Capdevila, C., Bardés, I., Alonso, G., Ferré, C., Soler, M., Máñez, R., Jaurrieta, E., Pujol, R. and Salazar, A. (2013) Alternatives to Conventional Hospitalization for Improving Lack of Access to Inpatient Beds: A 12-Year Cross-Sectional Analysis. Journal of Hospital Administration, 2, 9-21.

[33] Levin, S.R., Dittus, R., Aronsky, D., Weinger, M.B., Han, J., Boord, J., et al. (2008) Optimizing Cardiology Capacity to Reduce Emergency Department Boarding: A Systems Engineering Approach. American Heart Journal, 156, 12021209. http://dx.doi.org/10.1016/j.ahj.2008.07.007

[34] Epstein, A.M., Jha, A.K. and Orav, E.J. (2011) The Relationship between Hospital Admission Rates and Rehospitalizations. The New England Journal of Medicine, 365, 2287-2295. http://dx.doi.org/10.1056/NEJMsa1101942

[35] Bueno, H., Ross, J.S., Wang, Y., Chen, J., Vidán, M.T., Normand, S.L.T., et al. (2010) Trends in Length of Stay and Short-Term Outcomes among Medicare Patients Hospitalized for Heart Failure: 1993-2008. JAMA, 303, 2141-2147. http://dx.doi.org/10.1001/jama.2010.748 
Scientific Research Publishing (SCIRP) is one of the largest Open Access journal publishers. It is currently publishing more than 200 open access, online, peer-reviewed journals covering a wide range of academic disciplines. SCIRP serves the worldwide academic communities and contributes to the progress and application of science with its publication.

Other selected journals from SCIRP are listed as below. Submit your manuscript to us via either submit@scirp.org or Online Submission Portal.
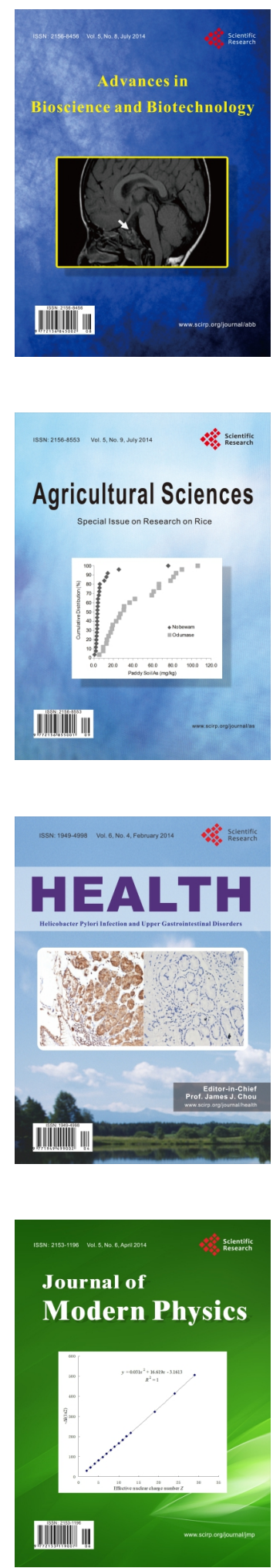
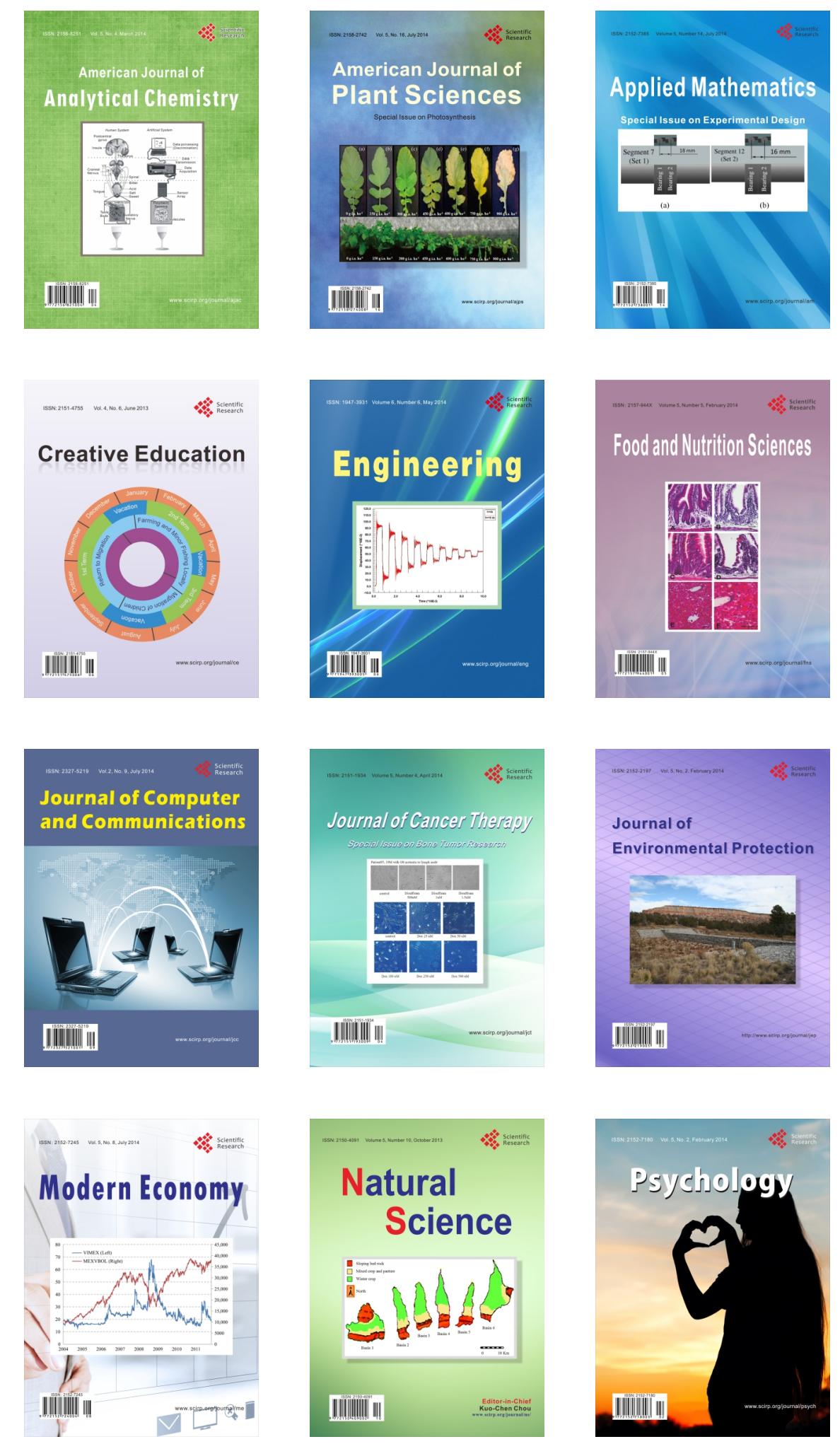